\title{
器 \\ Staphylococcus aureus enterotoxigênicos em leite de cabra e seus derivados, um risco à Saúde Pública
}

\author{
[Staphylococcus aureus enterotoxigenic in goat's milk and its derivatives, a risk to Public Health]
}

\section{"Revisão/Review"}

\author{
Breno Bezerra Aragão*, Sabrina Cândido Trajano, Rinaldo Aparecido Mota
}

Departamento de Medicina Veterinária, Universidade Federal Rural de Pernambuco, Recife-PE, Brasil.

*Autor para correspondência/Corresponding author: E-mail: breno.aragao100@ hotmail.com

\begin{abstract}
Resumo
A caprinocultura leiteira é considerada como uma das principais atividades agropecuárias da região Nordeste, sendo uma importante fonte de geração de renda e de empregos. Entretanto é uma atividade de baixa tecnificação, fato preocupante para a saúde pública, visto que o leite caprino e seus derivados podem ser importantes veiculadores de microrganismos causadores de Doenças Transmitidas por Alimentos. Dentre os microrganismos destaca-se o Staphylococcus aureus, agente infeccioso responsável por casos de intoxicação alimentar envolvendo o leite caprino e seus derivados. Apesar da importância, estudos sobre sua qualidade microbiológica ainda são escassos, sendo esta revisão um alerta quanto à necessidade de avaliação microbiológica do leite caprino e derivados comercializados no Nordeste brasileiro.
\end{abstract}

Palavras-chave: Staphylococcus aureus; intoxicação alimentar; enterotoxinas estafilocócicas; leite caprino.

\begin{abstract}
Dairy goat farming is considered as one of the main agricultural activities in the Northeast region, being an important source of income and jobs. However, it is a low-tech activity, a matter of concern for public health, since goat milk and its derivatives can be important carriers of microorganisms that cause Foodborne Diseases. Among the microorganisms, Staphylococcus aureus is an infectious agent responsible for cases of food poisoning involving goat milk and its derivatives. Despite the importance, studies on its microbiological quality are still scarce, and this review is an alert for the need for microbiological evaluation of goat milk and derivatives marketed in the Brazilian Northeast.
\end{abstract}

Keywords: Staphylococcus aureus; food poisoning; staphylococcal enterotoxins; goat's milk.

\section{Introdução}

A espécie caprina está distribuída em todos os continentes do planeta, sendo que as maiores concentrações estão nos países em desenvolvimento. Dentre os maiores produtores estão a China com 19,00\% do rebanho mundial, Índia com $13,00 \%$, Nigéria com 7,00\%, Paquistão com 6,60\% e Bangladesh (5,60\%) (CONAB, 2016).

O efetivo nacional de caprinos, de acordo com o censo realizado em 2015 pelo Instituto Brasileiro de Geografia e Estatística (IBGE) foi de 9,61 milhões de cabeças. Em termos regionais, 92,7\% deste efetivo está na Região Nordeste. Os do efetivo nacional, Bahia com 27,4\% e Pernambuco com 25,3\% do total, respectivamente, seguidos por Piauí $(12,8 \%)$ e Ceará $(11,6 \%)$, representando $83,3 \%$ do efetivo nacional da espécie (IBGE, 2015).

Apesar da importância da caprinocultura leiteira na região Nordeste, sua produção possui base familiar sem tecnificação e cuidados higiênico-sanitários adequados (Correia et al., 2001), fato que representa risco ao consumo, uma vez que o leite de cabra e seus derivados podem veicular diversos microrganismos patogênicos (Xing et al., 2016). 
Dentre esses agentes destaca-se Staphylococcus aureus (Zecconi e Hahn, 2000), que possui importância na epidemiologia das DTAs em decorrência do potencial risco zoonótico devido ao risco de produção de Enterotoxinas Estafilocócicas (EE), contaminando os alimentos e podendo causar gastrenterites alimentares (Wang et al., 2012; Xing et al., 2016).

A produção de EE é considerada a principal causa das intoxicações de origem bacteriana no homem, sendo relatada em diversos surtos de doenças transmitidas por alimentos (Cliver, 1994). Além das EE, algumas cepas do gênero Staphylococcus podem produzir a toxina-1 da síndrome do choque tóxico (TSST-1) (Todd et al., 1978; Spanu et al., 2012). A TSST-1 é responsável por uma doença sistêmica de caráter agudo, com febre alta, hipotensão e envolvimento de três ou mais órgãos sistêmicos (Chesney, 1989). Devido à importância das EE e TSST-1 e o impacto na saúde pública, vários estudos já foram realizados para detecção de genes toxigênicos em isolados de $S$. aureus, procedentes de amostras de leite de cabra e seus derivados (Orden et al. 1992; Scherrer et al. 2004).

S. aureus além de causar surtos de intoxicação alimentar (Johler et al. 2015), pode ser responsável por infecções persistentes de difícil tratamento devido a fatores de virulência e resistência a antimicrobianos (Franklin, 2003; Velázquez-Meza, 2005).

Apesar da importância da caprinocultura leiteira na região Nordeste do Brasil, não há estudos que elucidem a importância do leite de cabra e seus derivados associados à saúde pública e Doenças Transmitidas por Alimentos (DTAs) que cepas de $S$. aureus enterotoxigênicos podem causar. Desta forma, objetivou-se com esta revisão de literatura evidenciar a importância de S. aureus como um dos principais agentes causadores de DTAs e com ênfase em leite caprino e seus derivados.

\section{Leite Caprino e Seus Derivados}

O leite de cabra é definido pela Instrução Normativa de $\mathrm{n}^{\mathrm{o}} 37 / 2000$ do Ministério da Agricultura, Pecuária e Abastecimetno (MAPA), como um produto originado de ordenha higiênica, completa e ininterrupta de cabras saudáveis, bem alimentadas e em descanso. As características sensoriais do leite de cabra são: cor branca, sabor e odor especiais, mas não desagradáveis (BRASIL, 2000).
No Brasil, a identidade e qualidade do leite de cabra são regulamentadas pela Instrução normativa de $n^{\circ} 37 / 2000$ (BRASIL, 2000) que fixa as condições de produção, a identidade e os requisitos mínimos de qualidade do leite de cabra destinado ao consumo humano. Ainda, determina teores mínimos de proteína $(2,8 \%)$, lactose $(4,3 \%)$ e cinzas $(0,7 \%)$ e acidez podendo variar entre 0,13 a $0,18 \%$.

O regulamento de padrões de qualidade de leite de cabra é de extrema importância, já que a partir do leite caprino obtido pela ordenha, é possível beneficiá-lo e obter diversos derivados como iogurtes, bebidas lácteas, doces e queijo, por meio de técnicas de elaboração simples e acessíveis aos pequenos caprinocultores, alternativa está para o aumento do consumo de produtos e agregação de valor como estímulo à produção (Santos et al., 2011).

A produção de leite de cabra e o aumento de sua demanda pode ser caracterizada por alguns aspectos gerais, sendo considerada uma importante fonte de obtenção de carne, leite e derivados para população de áreas rurais de baixa renda. Existe grande procura do leite e derivados nos países desenvolvidos como de alto padrão de qualidade (produtos gourmets), tais como os queijos finos elaborados com leite de cabra, além destes, o leite caprino é tido como uma importante fonte nutricional, e também é considerado um produto alternativo para aqueles que sofrem de alergia ao leite de vaca e/ou outras patologias gastrointestinais (Haenlein, 2004).

O leite caprino quando comparado com o leite bovino, apresenta na sua composição o predomínio de $\beta$-caseína, K-caseína e menores teores de $\alpha \mathrm{S} 1$-caseína; ainda, em relação à composição, o lactosoro caprino possui uma menor quantidade de albumina sérica e lactoalbumina; estes teores são uma vantagem para pessoas que sofrem com processos alérgicos ao leite de vaca (Businco e Bellanti, 1993). Estas características físico-químicas tornam o leite caprino e seus derivados, produtos de elevada digestibilidade e para fins terapêuticos (Bueno, 2005), sendo considerados hipoalergênicos (Ribeiro e Ribeiro, 2010).

O leite caprino e seus derivados, além de serem considerados alimentos de grande importância nutricional e terapêutica para os seres humanos (Ribeiro e Ribeiro, 2010; Slačanac et al., 2010), ainda exercem grande importância econômica (Andrade et al., 2012). Apesar da 
relevância da caprinocultura leiteira e de seus derivados, existem alguns entraves neste segmento, uma vez que é desenvolvido de forma rudimentar e vinculado à produção familiar, baixa tecnificação, pouca eficiência dos sistemas de produção praticados, bem como, da inexistência de tecnologias de processamento e elaboração dos produtos derivados (Queiroga et al., 2013).

Considerando a importância econômica e o impacto à saúde pública que as falhas de elaboração de queijos artesanais no estado de Pernambuco poderiam gerar, no ano de 1992 foi criado o Decreto de $\mathrm{n}^{\circ} 15.839$ que posteriormente foi alterado no ano de 2007 pela Lei ${ }^{\circ} 13.376$. A Lei estadual de $n^{\circ} 13.376$ visa a inocuidade dos queijos artesanais, bem como o seu modo de elaboração e exige condições higiênico-sanitárias mínimas de elaboração e segurança microbiológica (ALEPE LEGIS, 2007).

As falhas no sistema de produção da caprinocultura leiteira, além de causar perdas econômicas (Cordeiro, 2006) é um sério problema para Saúde Pública, pois estes podem constituir um risco à saúde do consumidor (Silva et al., 2015), uma vez que, o leite caprino e seus derivados podem veicular microrganismos patogênicos e causar surtos de Doenças Transmitidas por Alimentos (Stewart, 2005; Xing et al., 2016; Klimešová et al., 2017).

\section{Doenças Transmitidas por Alimentos}

As Doenças Transmitidas por Alimentos (DTAs) são definidas pela Organização Mundial da Saúde como "afecções de origem infecciosa ou tóxica causadas pelo consumo de alimentos ou água" (WHO, 2017). Atualmente existe uma grande preocupação por parte dos consumidores e de órgãos fiscalizadores referentes à qualidade $\mathrm{e}$ segurança dos alimentos; neste sentido as DTAs possuem grande relevância ao serem tratadas como um sério problema para a saúde pública (Santana et al., 2010).

Nos últimos anos as DTAs tiveram um grande destaque estando muitas vezes associadas a fatores de nível econômico, processo de globalização do comércio de alimentos, aumento da urbanização (Abreu et al., 2001), além de mudanças nos hábitos alimentares dos consumidores, que estão dando preferência a alimentos frescos ou in natura, prontos ou semiprontos e por realizar um maior número de refeições fora do domicílio (Sahyon, 2002; Tomasi e Spazziani, 2008).
São diversas as causas de contaminação dos alimentos e desta forma a Organização Mundial de Saúde tem salientado a importância da inocuidade e o risco de danos à saúde que os alimentos contaminados podem causar (Joob e Wiwanitkit, 2015). No Brasil, de acordo com o levantamento epidemiológico sobre a frequência de surtos de DTAs, no ano de 2013 foram notificados 861 surtos que resultaram em 17.455 doentes; no ano seguinte foram registrados 886 surtos com 15.700 doentes. No levantamento realizado em 2016, o número de surtos notificados foi de 543 surtos e 9.907 doentes, sendo a região Sudeste a que possui a maior frequência de notificação de surtos no país (BRASIL, 2017).

Em um levantamento realizado pela Secretaria de Saúde de Pernambuco (2017) entre os anos de 2002 e 2011 foram confirmados 551 surtos de DTAs, que ocasionaram aproximadamente 10.029 doentes e 14 óbitos. Em 2012 foram registrados 59 surtos que resultaram em 1.135 doentes. A frequência dos casos de surtos de DTAs foi mais frequente na $1^{\circ}$ Gerência Regional de Saúde (abrange os municípios da região Metropolitana do Recife e a Ilha de Fernando de Noronha) com aproximadamente 82,2\% (SES, 2017).

Dos casos notificados em Pernambuco, a maior parte dos surtos notificados $(36,3 \%)$ ocorreu em estabelecimentos comerciais de alimentação (lanchonetes, restaurantes, bares e padarias). Em seguida, vêm os casos ocorridos em residências domésticas com frequência de $28,1 \%$ dos casos (SES, 2017).

De acordo com a literatura, existem mais de 250 tipos de DTAs descritas, dentre elas: botulismo, salmonelose, cólera, intoxicação por enterotoxinas estafilocócicas, entre outras, as quais são cosmopolitas, ocorrendo principalmente em países em desenvolvimento (Le Loir et al., 2003). Os alimentos de maneira geral estão suscetíveis às contaminações por diferentes agentes etiológicos, que podem causar doenças devido a ações do seu próprio desenvolvimento ou pela ação de toxinas (Stamford et al., 2006).

Dentre as afecções causadas pelas DTAs, é importante ressaltar a diferença existente entre a infecção alimentar e a intoxicação alimentar. A infecção alimentar é um quadro caracterizado pela ingestão de microrganismos viáveis no alimento, em quantidade suficiente para causar o aparecimento de sintomas após passarem pelas barreias protetoras do organismo humano. $\mathrm{Na}$ 
intoxicação alimentar, os microrganismos produzem toxinas no alimento que ao ser ingerido resultará nos sintomas (Poulsen, 2015).

Os distúrbios causados por essas afecções podem se apresentar de diversas formas, caracterizando-se como uma síndrome onde frequentemente estão presentes os sintomas de anorexia, náuseas, vômitos e/ou diarreia e febre. A ingestão de alimentos ou água contaminados por agentes patogênicos podem também causar doenças extra intestinais envolvendo órgãos como os rins e o fígado, assim como o sistema nervoso central (BRASIL, 2017).

Dentre os microrganismos causadores de DTAs destaca-se o Staphylococcus aureus (Njage et al., 2013). Esse microrganismo é considerado a principal causa de intoxicações alimentares e da Síndrome do choque tóxico em todo o mundo devido à produção EE e TSST-1 (Dinges et al., 2000; Oliver et al., 2009; Tong et al., 2015). A alta frequência de $S$. aureus em alimentos tem uma importante associação com a manipulação e condições higiênicas inadequadas na obtenção e sua elaboração, bem como nas etapas de transporte e refrigeração inadequadas (Argudin et al., 2010).

Os alimentos mais incriminados nos casos de intoxicação alimentar estafilocócica são as carnes de frango, ovos de galinha de capoeira, saladas, produtos de panificação (doces, bolos confeitados), sanduíches (Wieneke et al., 1993) e em especial os produtos lácteos (Zweifel et al., 2006; Oliver et al., 2009). Dentre os alimentos, os produtos lácteos são mais suscetíveis à contaminação por $S$. aureus e na Europa foram responsáveis por 5\% dos surtos ocorridos (Bianchi et al., 2014).

Os queijos artesanais elaborados com leite caprino detém grande importância nesse aspecto, pois normalmente não sofrem tratamento térmico, o que eleva o risco de contaminação por microrganismos patogênicos que ocasionalmente podem causar surtos de intoxicação alimentar; os queijos artesanais caprinos já foram incriminados em surtos de intoxicação alimentar (De Buyser et al., 1985; Wieneke e Gilbert, 1987; Johler et al., 2015).

\section{Staphylococcus aureus}

Staphylococcus aureus pertence à família Staphylococcaceae que possui mais de 52 espécies e 28 subespécies (Euzéby, 2018). É uma bactéria que se apresenta em forma de cocos, com tamanho variando de 0,5 a 1,5 micrômetros de diâmetro. É uma bactéria Gram positiva e pode se apresentar em apenas uma célula, em pares ou tétrades em forma que lembra o cacho de uva; são anaeróbios facultativos, crescendo melhor em ambientes de aerobiose, é catalase positivo, imóveis e não possuem a capacidade de esporular (Bergdoll, 1989; Kloss e Schleifer, 1984).

De modo geral, são microrganismos mesófilos típicos, com temperatura ótima de crescimento de $35^{\circ} \mathrm{C}$, porém podem crescer em temperatura variável entre 7 a $47,8^{\circ} \mathrm{C}$. O potencial de Hidrogênio ideal é de 7,0 e 7,5, sendo resistente às variações de 4,2 a 9,3 (Kloss e Schleifer, 1984; FDA, 2012). Em alimentos, S. aureus desenvolvese bem até naqueles que possuem atividade de água de $0,83 \mathrm{~W}$, sendo considerado o valor ótimo de 0,99W (Bergdoll, 1990; FDA, 2012). É considerado também um microrganismo halotolerante, crescendo em alimentos que contêm até $20 \%$ de $\mathrm{NaCl}$ e são bactérias termolábeis, sendo inativadas a temperaturas superiores a $60^{\circ} \mathrm{C}$ por três minutos (Bergdoll, 1989; FDA, 2012).

Sua distribuição é ampla na natureza, sendo resistente à dessecação e ao frio e pode permanecer viável por longos períodos em partículas de poeira. $S$. aureus pode infectar diversos animais, causando enfermidade ou não. A infecção por $S$. aureus em bovinos leiteiros é mais frequente quando comparada aos ovinos e caprinos (Moroni et al., 2005), porém podem veicular o agente em casos de mastite em cabras leiteiras (Stewart, 2005).

No homem, a prevalência do $S$. aureus pode variar de $40 \%$ (Bannerman, 2003) a $60 \%$ (Cassettari et al., 2005) em sítios anatômicos, como no conduto nasal, na garganta, na superfície da pele, sendo mais frequente nas mãos, braços, rosto e feridas (Kluytmans e Wertheim, 2005; Argudin et al., 2010).

Nesse sentido, $S$. aureus pode ser um importante indicador de higiene pessoal e de avaliação de programas de sanitização de indústrias lácteas (Pales et al., 2005), devido ao potencial de formação de biofilmes, elevando o risco de transmissão e contaminação de alimentos (Akbas et al., 2015). Estudos demonstraram que uma das vias mais frequentes de transmissão e contaminação de alimentos por S. aureus é via manipulador, além de indivíduos doentes ou portadores assintomáticos (Bryan, 1988; Carmo et al., 2003; Argudin et al., 2010). Esses fatores, aliados às falhas higiênico-sanitárias no processamento e manipulação, podem contaminar os alimentos e dar origem a surtos de DTAs 
(Gomes e Gallo, 1995; Carmo et al., 2003; Becker et al., 2007).

S. aureus é considerado uma das bactérias mais estudadas, devido a sua importância na epidemiologia da mastite em rebanhos leiteiros, além da considerável perda de dias úteis e produtividade, custos gerados com atendimento médico e hospitalar (Balaban e Rasooly, 2000), perdas econômicas para a indústria alimentícia (Ribeiro et al., 2003). S. aureus é conhecido como um patógeno de importância mundial para saúde pública, em decorrência da sua resistência a antimicrobianos (Jamali et al., 2015) e produção de EE (Tong et al., 2015).

\section{Características Genéticas dos Genes Codificadores de Enterotoxinas}

Os genes codificadores de enterotoxinas conferem a $S$. aureus a capacidade de produção de enterotoxinas que podem causar quadros de intoxicação alimentar quando ingeridas (Hennekinne et al., 2012). A expressão desses genes (produção das EE) está associada a diversos fatores, como temperatura (Tutsuura e Murata, 2013), número de células viáveis, concentração do microrganismo, concentração de sal, pH (Balaban e Rasooly, 2001; Brasca et al., 2005), além da competição da microbiota presente (Necidová et al., 2009).

O entendimento aprofundado dos genes codificadores de enterotoxinas estafiliccócicas se deu em 1984, quando foi descrito a partir da clonagem da Enterotoxina Estafilocócica A (EEA), por meio da técnica de transferência de DNA cromossomal de $S$. aureus enterotoxigênico portador de genes codificadores de enterotoxina (Betley et al., 1984).

\section{Gene Codificador sea}

O gene sea quando expresso confere a $S$. aureus a capacidade de produção da EEA. São carreados em profagos (Balaban e Rasooly, 2000), sendo composto por 771 pares de bases nucleotídicas; é responsável pela codificação do precursor de enterotoxina A, composta por 257 resíduos de aminoácidos (Betley e Mekalanos, 1988). Esta molécula é processada na base de 24 resíduos $\mathrm{N}$ - terminais que dará origem a partícula ativa (Tremaine et al., 1993).

\section{Gene Codificador $s e b$}

O gene seb é outro tipo de gene codificador de EE e sua origem pode ser cromossomal (Shafer e Iandolo, 1978) e/ou plasmideal (Shalita et al., 1977). O gene seb é composto por 798 nucleotídeos que quando expresso produzirá uma proteína precursora da EEB formada por 266 aminoácidos (Jones e Khan, 1986).

\section{Gene Codificador $\mathrm{sec}$}

$\mathrm{O}$ gene sec possui sua origem na região cromossomal conservada e quando é expresso pode originar os três subtipos de EE: (EEC1, EEC2 e EEC3), sendo distinguidas antigenicamente (Marrack e Kappler, 1990). Apesar das diferenças antigênicas dos três subtipos de EE, exibem uma homologia de $97 \%$ na sequência de aminoácidos (Nagaraj et al., 2016). O gene sec é composto por 801 pares de bases, estes formam três regiões: $\mathrm{sec} 1$, $\sec 2$ e $\sec 3$ que ao serem expressas darão origem a EEC1, EEC2 e EEC3 respectivamente.

A região $\sec 1$ ao ser expressa formará uma proteína precursora da EEC1 composta por de 266 aminoácidos, ao final do processamento no retículo plasmático rugoso, a molécula finalizada será composta por 296 aminoácidos (Bohach e Schlievert, 1987). Já a região $\sec 2$, ao ser expressa produzirá a EEC2, composta por uma molécula ativa de 255 resíduos de aminoácidos (Robern et al., 1975). A região sec3 codifica a EEC3, que é tida como altamente emética e sua formação é composta por 236 resíduos de aminoácidos (Reiser et al., 1984).

\section{Gene Codificador sed}

$\mathrm{O}$ gene sed também possui sua origem plasmidial de 27,6 Kb denominado de piB485. Este gene é composto por 258 aminoácidos e ao passar pelo processo de expressão genética dará origem a proteína percursora da EED formada por 228 aminoácidos (Bayles e Iandolo, 1989).

\section{Gene Codificador see}

O gene sea quando expresso confere a $S$. aureus a capacidade de produção da EEE. Este gene possui sua origem cromossomal (Betley e Mekalanos, 1988), e é composto por 771 pares de base nucleotídicas; sua expressão dá origem a uma proteína precursora formada por 214 resíduos de aminoácidos (Couch et al., 1988).

\section{Gene Codificador $t s t$,}

$\mathrm{O}$ gene $t$ ts possui sua origem cromossomal e é responsável por codificar a produção da Toxina da Síndrome do Choque Tóxico (TSST-1). Este gene é formado por 708 pares de bases 
nucelotídicas (Blomster-Hautamaa et al., 1986), e o gene pode ser encontrado nas ilhas de patogenicidade de cepas de $S$. aureus, podendo estar inseridos tanto na região próxima a $\operatorname{tyr} B$ (SAPI1), quanto em trp (SAPI2) (Lindsay et al., 1998).

\section{Enterotoxinas Estafilocócicas}

As EE são resultantes da expressão dos genes codificadores. São importantes exotoxinas sintetizadas por $S$. aureus ao longo da fase de crescimento logarítmica ou na fase de transição do crescimento exponencial para a fase estacionária (Otero et al., 1990; Betley et al., 1992) e podem causar distúrbios gastrointestinais (Zecconi e Hahn, 2000). Para que ocorra o quadro de intoxicação alimentar basta haver a ingestão de pequena dose (Bergdoll, 1979; Larkin et al., 2009; FDA, 2012) que pode variar de 20 a 200ng de EE (Evenson et al., 1988; Normanno et al.,2007).

As EE são formadas por cadeias de proteínas simples e de baixo peso molecular de 26.000 a 30.000 daltons (Soriano et al., 2002). São resistentes ao processo de pasteurização e não são inativadas pelos produtos originados da fermentação de outros microrganismos (Loncarevic et al., 2005), onde uma vez produzida, permanece no alimento mantendo sua atividade biológica (Becker et al., 2007). Além da resistência das EE no processamento tecnológico, não são inativadas pela ação de proteases presentes no trato gastrointestinal (pepsina) (Loncarevic et al., 2005).

A ingestão de EE pode causar o quadro intoxicação alimentar caracterizados por vômito, náuseas, diarreia, dores abdominais, com período de incubação de uma a seis horas após a ingestão do alimento contaminado (Passos et al., 1996; Pereira et al., 1996; Hennekinne et al., 2012). A duração do quadro geralmente é curta (24 a 48 horas) e a recuperação do doente pode ocorrer de um a três dias (Holmberg e Blake, 1984). A intoxicação estafilocócica é branda, auto limitante, com baixa taxa de mortalidade (Holmberg e Blake, 1984), porém é considerada uma das principais intoxicações de origem bacteriana no homem, sendo relatada em diversos surtos de doenças transmissíveis por alimentos (Cliver, 1994; Brasca et al., 2005).

As EEs pertencem ao grupo de toxina pirogênica da família de superantígenos como a toxina da síndrome do choque tóxico (TSST-1) (Dinges et al., 2000), sendo esta responsável por gerar uma resposta hiperimune no hospedeiro, com proliferação de linfócitos $\mathrm{T}$ independentemente da especificidade do antígeno destas células (Schlievert et al., 2000; Cha et al., 2007). De acordo com o Comitê de Nomenclatura Internacional para a Nomenclatura de Superantígenio Staphylococcal (sigla em inglês INCSSN), as EEs podem ser classificadas de acordo com sua capacidade de atividade emética ou não, após a administração oral em primatas (Lina et al., 2004; Omoe et al., 2005).

De acordo com a literatura, até o momento foram descritas $23 \mathrm{EEs}$, sendo classificadas como EEs eméticas os tipos: EEA, EEB, EEC, EED, EEE, EEG, EEH, EEI, EER, EES, EET (Argudin et al., 2010; Wilson et al., 2011; Hennekinne et al., 2012), EEY (Ono et al., 2015). Além destas, existem as EEs não eméticas: EEJ, EEK, EEL, EEM, EEN, EEO, EEP, EEQ, EEU, EEV, EEX (Argudin et al., 2010; Wilson et al., 2011; Hennekinne et al., 2012) e também a Toxina da Síndrome do Choque Tóxico classificada inicialmente de EEF sem atividade emética (Reiser et al., 1983; Bergdoll, 1997).

Dentre as EEs citadas são consideradas como clássicas a EEA, EEB, EEC, EED e EEE. Estas são tidas como mais relevantes devido ao número elevado de casos que foram associadas aos surtos de intoxicação alimentar (Argudin et al., 2010). Em estudos foram detectadas frequências de até $95 \%$ de surtos de intoxicação alimentar causados pelas EE A, B, C, D e E (Jarraud et al., 1999; Letertre et al., 2003; Pelisser et al., 2009).

\section{Considerações Finais}

O potencial do leite caprino e seus derivados são cada vez mais evidenciados nas pesquisas realizadas, além de ser considerado uma importante fonte de renda e de geração de empregos na região Nordeste. Entretanto estudos sobre a qualidade microbiológica dos produtos elaborados na cadeia produtiva de leite caprino e seus derivados ainda são escassos, fato preocupante para saúde pública, uma vez que microrganismos patogênicos tais como Staphylococcus aureus enterotoxigênicos podem ser veiculados por esses alimentos, assim é realizado um alerta, quanto a necessidade de avaliação microbiológica do leite caprino e derivados comercializados no Nordeste brasileiro.

\section{Referências}

Abreu, E.S.; Viana, I.C.; Moreno, R.B.; Torres, E.A.F.S. Alimentação mundial - uma reflexão 
sobre a história. Saúde e Sociedade, 10(2): 314,2001

Andrade, N.P.C.; Peixoto, R.M.; Nogueira, D.M.; Krewer, C.C.; Costa, M.M. Perfil de sensibilidade aos antimicrobianos de Staphylococcus spp. coagulase negativa de um rebanho leiteiro caprino em Santa Maria da Boa Vista - PE. Medicina Veterinária, 6(1): $1-6,2012$.

Argudin, M.A.; Mendoza, M.C.; Rodicio, M.R. Food poisoning and Staphylococcus aureus enterotoxins. Toxin, 2(7): 1751-1774, 2010.

Akbas, M.Y.; Kokumer, T. The prevention and removal of biofilm formation of Staphylococcus aureus strains isolated from raw milk samples by citric acid treatments. International Journal of Food Science \& Technology, 50(7): 1666-1672, 2015.

Balaban, N.; Rasooly, A. Analytical chromatography for recovery of small amounts of staphylococcal enterotoxins from food. International Journal of Food Microbiology, 64(1-2): 33-40, 2001.

Bannerman, T.L. Staphylococcus, Micrococcus and other catalase-positive cocci that aerobically. In: Murray, P.R. (Ed.). Manual Clinical Microbiology. $8^{\circ}$ Ed. Washington: ASM Press, 2003. v.1, p.384-404.

Bayles, K.W.; Iandolo, J.J. Genetic and molecular analyses of the gene encoding Staphylococcal enterotoxin D. Journal of Bacteriology, 171(9): 4799-806, 1989.

Becker, H.; Bürk, C.; Märtlbauer, E. Staphylokokken-Enterotoxine: Bildung, Eigenschaften und Nachweis. Journal für Verbraucherschutz und Lebensmittelsicherheit, 2(2): 171-189, 2007. Bergdoll, M.S. Staphylococcal infections. Foodborne Infections and Intoxications, $2^{\circ} \mathrm{Ed}$., New York: Academic Press, 1979, p.443-494. Bergdoll, M.S. Staphylococcus aureus. In: DOYLE, M.P. (Ed.) Foodborne bacterial pathogens. New York: Marcel Dekker Inc., 1989, cap.11, p.463-523.

Bergdoll, M.S. Staphylococcal food poisoning. In: CLIVER, D.O. (Ed.) Foodborne diseases. San Diego: Academic Press Inc., 1990, cap.5, p.85-106.

Bergdoll, M.S. Toxic shock syndrome. Journal of Venomous Animals and Toxins, 3(1): 6-21, 1997.

Betley, M.J.; Borst, D.W.; Regassa, L.B. Staphylococcal enterotoxins, toxic shock syndrome toxin and streptococcal pyrogenic exotoxins: a comparative study of their molecular biology. Chemical Immunology, 55: 1-35, 1992.

Bianchi, D.M.; Gallina, S.; Bellio, A.; Chiesa, F.; Civera, T.; Decastelli, L. Enterotoxin gene profiles of Staphylococcus aureus isolated from milk and dairyproducts in Italy. Letters in Applied Microbiology, 58(2): 190-196, 2014.

Blomster-Hautamaa, D.A.; Kreiswirth, B.N.; Kornblum, J.S.; Novick, R.P.; Schlievert, P.M. The nucleotide and partial amino acid sequence of toxic shock syndrome toxin-1. Journal of Biological Chemistry, 261(33): 15783-6, 1986

Bohach, G.A.; Schlievert, P.M. Nucleotide sequence of the staphylococcal enterotoxin $\mathrm{Cl}$ gene and relatedness to other pyrogenic toxins. Molecular Genetics and Genomics, 209(1): 15-20, 1987.

Brasca, M.; Morandi, S.; Vanoni, L.; Colombo, L.; Lodi, R. The influence of different cultural conditions on the development and toxinogenesis of Staphylococcus aureus. Scienza Tecnica Lattiero Casearia, 56: 105115, 2005.

BRASIL. Ministério da Agricultura, Pecuária e Abastecimento. Instrução Normativa $\mathbf{N}^{\circ} 37$ de 31 de outubro de 2000. Diário Oficial da União. Brasília, DF, 8 de novembro de 2000.

BRASIL. Ministério da Saúde. Surtos de Doenças Transmitidas por Alimentos no Brasil. Unidade de Vigilância das Doenças de Transmissão Hídrica e Alimentar, 2017. Disponível em <http://portalarquivos.saude.gov.br/images/p df/2017/maio/29/Apresent acaoSurtosDTA2017.pdf>. Acesso em: 14/07/2018.

Bryan, F.L. Risks of practices, procedures and processes that lead to outbreaks of foodborne diseases. Journal of Food Protection, 51(8): 663-73, 1988.

Bueno, M.C. Leite de cabra: excelente alimento funcional. Revista Leite e Derivados. n.83, p.52, 2005.

Businco, L.; Bellanti, J. Food allergy in childhood. Hypersensitivity to cow's milk allergens. Clinical and Experimental Allergy, 23: 4813, 1993.

Carmo, L.S.; Dias, R.S.; Linardi, V.R.; Sena, M.J.; Santos, D.A. An outbreak of staphylococcal food poisoning in the municipality of Passos, 
MG, Brazil. Brazilian Archives of Biologyand Technology, 46(4): 581-6, 2003. Cassettari, V.C.; Strabelli, T.; Medeiros, E.A.S. Staphylococcus aureus bacteremia: what is the impact of oxacillin resistance on mortality? Brazilian Journal of Infectious Diseases, 9(1): 70-6, 2005.

Cha, J.; Vakulenko, S.B.; Mobashery, S. Characterization of the betalactam antibiotic sensor domain of the MecR1 signal sensor/transducer protein from MethicillinResistant Staphylococcus aureus. Biochemistry, 46(26): 7822-7831, 2007.

Chesney, P.J. Clinical aspects and spectrum of illness of toxic shock syndrome: overview. Journal Infectious Diseases, 11(1): 51-57, 1989.

Cliver, D.O. Foodborne disease handbook: diseases caused by bacteria. Marcel Dekker. 1994, p.613.

CONAB - COMPANHIA NACIONAL DE ABASTECIMENTO. Conjuntura Trimestral Caprino-Ovinocultura Pernambuco, 2016. Disponível em: <http://www.conab.gov.br/OlalaCMS/upload s/arquivos/16_07_29_16_55_32_caprinovino cultura_-_jun_2016_-sureg_pe.pdf>. Acesso em: 18 jul. 2018.

Cordeiro, P.R.C. Mercado do leite de cabra e de seus derivados. Revista do Conselho Federal de Medicina Veterinária, 12(39): 32-43, 2006.

Correia, R.C.; Moreira, J.N.; Araújo, J.L.P. Cadeia produtiva de caprinos ovinos do vale do rio Gavião: elementos para tomada de decisão. Petrolina-PE: Embrapa Semi-Árido. p.39, 2001.

Couch, J.L.; Soltis, M.T.; Betley, M.J. Cloning and Nucleotide Sequence of the Type E Staphylococcal Enterotoxin Gene. Journal of Bacteriology, 170(7): 2954-60, 1988.

De Buyser A.L.; Janin, F.; Dilasserf. Contamination of ewe cheese with Staphylococcus aureus: study of an outbreak of food poisoning. Zentralblatt fur Bakteriologie, Mikrobiologie and Hygiene I, 14(1): 677-678, 1985.

Dinges, M.M.; Orwin, P.M.; Schlievert, P.M. Exotoxins of Staphylococcus aureus. Clinical Microbiology Reviews, 13(1): 16-34, 2000.

Evenson, M.L.; Hinds, M.W.; Bernstein, R.S.; Bergdoll, M.S. Estimation of human dose of staphylococcal enterotoxin A from a large outbreak of staphylococcal food poisoning involving chocolate milk. International Journal of Food Microbiology, 7(4): 311316, 1988.

Euzéby, J.P. List of Prokaryotic names with Standing in Nomenclature. Disponível em <http://www.bacterio.net/staphylococcus.htm 1>. Acesso em: 23 jun. 2018.

FDA - FOOD AND DRUG ADMINISTRATION. Bad bug book. Handbook of foodborne pathogenic microorganisms and natural toxins, 2012. Disponível em: <http://www.fda.gov/downloads/Food/FoodS afety/FoodborneIllness/FoodborneIllnessFoo dbornePathogensNaturalToxins/BadBugBoo k/UC297627.pdf> Acesso em: 15 jun. 2018.

Franklin, D.L. Antimicrobial resistance: the example of Staphylococcus aureus. Journal of Clinical Investigation, 111(9): 1265-1273, 2003.

Gomes, H.A.; Gallo, C.R. Ocorrência de e produção de enterotoxinas por linhagens isoladas a partir de leite cru, leite pasteurizado tipo C e queijo Minas Frescal comercializados em Piracicaba-SP. Ciência e Tecnologia de Alimentos, 15: 158-61, 1995.

Haenlein, G.F. Goat milk in human nutrition. Small Ruminant Research, 51(2): 155-63, 2004.

Hennekinne, J.A.; De Buyser, M.L.; Dragacci, S. Staphylococcus aureus and its food poisoning toxins: characterization and outbreak investigation. FEMS Microbiology Reviews, 36(4): 815-836, 2012.

Holmberg, S.D; Blake, P.A. Staphylococcal food poisoning in the United States: new facts and old misconceptions. Journal of American Medical Association, 251(4): 487-9, 1984.

IBGE - INSTITUTO BRASILEIRO DE GEOGRAFIA E ESTATÍSTICA. Produção da Pecuária Municipal. v.43, p.23, 2015. Disponível em: <http://biblioteca.ibge.gov.br/visualizacao/pe riodicos/84/ppm_2015_v43_br.pdf>. Acesso em 09 jun. 2018.

Jamali, H.; Paydar, M.; Radmehr, B.; Ismail, S.; Dadrasnia, A. Prevalence and antibiotic resistance of Staphylococcus aureus isolated from raw milk and dairy products. Food Control, 54: 384-388, 2015.

Jarraud, S.; Cozon, G.; Vandenesch, F.; Etienne, M.B; Lina, G. Involvement of enterotoxins $G$ and I in staphylococcal toxic shock syndrome 
and staphylococcal scarlet fever. Journal of Clinical Microbiology, 37(8): 2446-2449, 1999.

Johler, S.; Giannini, P.; Jermini, M.; Hummerjohann, J.; Baumgartner, A.; Stephan, R. Further Evidence for Staphylococcal Food Poisoning Outbreaks Caused by gc-Encoded Enterotoxins. Toxins, 7(3): 997-1004, 2015.

Jones, C.L.; Khan, S.A. Nucleotide sequence of the enterotoxin B gene from Staphylococcus aureus. Journal of Bacteriology, 166(1): 2033, 1986.

Joob, B.; Wiwanitkit, V. Food poisoning outbreak in Thailand: A review on situations. Asian Pacific Journal of Tropical Disease, 5(1): 187-189, 2015.

Klimešová, M.; Manga, I.; Nejeschlebová, L.; Horáček, J.; Ponížil, A.; Vondrušková, E. Occurrence of Staphylococcus aureus in cattle, sheep, goat, and pig rearing in the Czech Republic. Acta Veterinaria Brno, 86(1): 3-10, 2017.

Kloss, W.E.; Schleifer, K.H. Genus IV Staphylococcus Rosenbach 1884. In: Sneath, P.H.A.; Mair, N.S.; Sharpe, M.E. (Eds.). Bergey's Manual ${ }^{\circledR}$ of Determinative Bacteriology. Baltimore: The Williams \& Wilkins Co. 1984, 2:1013-1035.

Kluytmans, J.A.J.W.; Wertheim, H.F.L. Nasal carriage of Staphylococcus aureus and prevention of nosocomial infections. Infection, 33(1): 3-8, 2005.

Larkin, E.A.; Carman, R.J.; Krakauer, T.; Stiles, B.G. Staphylococcus aureus: the toxic presence of a pathogen extraordinaire. Current Medicinal Chemistry, 16(30): 4003-19, 2009.

ALEPE LEGIS - LEGISLAÇÃO DO ESTADO DE PERNAMBUCO. Lei ${ }^{\circ} 13.376$, de 20 de dezembro de 2007. Dispõe sobre o processo de Produção do Queijo Artesanal e dá outras providências. Disponível em $<$ http://legis.alepe.pe.gov.br/texto.aspx?id=6 392\& tipo=TEXTOORIGINAL>. Acesso em: 22 jun. 2018.

Le Loir, Y.; Baron, F.; Gautier, M. Staphylococcus aureus and food poisoning. Genetics and Molecular Research, 2(1): 63-76, 2003.

Letertre, C.; Perelle, S.; Dilasser, F.; Fach, P. Detection and genotyping by real-time PCR of the staphylococcal enterotoxin genes SEA to
SEJ. Molecular and Cellular Probes, 17(4): 139-47, 2003.

Lina, G.; Bohach, G.A.; Nair, S.P.; Hiramatsu, K.; Jouvin-Marche, E.; Mariuzza，R. Standard nomenclature for the superantigens expressed by Staphylococcus. Journal of Infectious Diseases, 189(12): 2334-6, 2004.

Lindsay, J.A.; Ruzin, A.; Ross, H.F.; Kurepina, N.; Novick, N.P. The gene for toxic shock toxin is carried by a family of mobile pathogenicity islands in Staphylococcus aureus. Molecular Microbiology, 29(2): 527-43, 1998.

Loncarevic, S.; Jorgensen, H.J.; Lovseth, A.; Mathisen, T.; Rorvik, L.M. Diversity of Staphylococcus aureus enterotoxin types within single samples of raw milk and raw milk products. Journal of Applied Microbiology, 98(2): 344-50, 2005.

Marrack, P.; Kappler, J. The staphylococcal enterotoxins and their relatives. Science. 248(4956): 705-11, 1990.

Moroni, P.; Pisoni, G.; Ruffo, G.; Boettcher, P.J. Risk factors for intramammary infections and relationship with somatic-cell counts in Italian dairy goats. Preventive Veterinary Medicine, 69(3-4): 163-173, 2005.

Nagaraj, S.; Ramlal, S; Venkataswamachari, B.P.; Paul, S.; Kingston, J.; Batra, H.V. Differentiation of entC1 from entC2/entC3 with a single primer pair using simple and rapid SYBR Green-based RT-PCR melt curve analysis. Applied Microbiology and Biotechnology, 100(19): 8495-506, 2016.

Necidová, L.; Štástková, Z.; Pos Píšilová, M.; Janš Tová, B.; Strejček, J.; Dušková, M.; Karpíšková, R. Influence of soft cheese technology on the growth and enterotoxin production of Staphylococcus aureus. Czech Journal of Food Sciences, 27(2): 127-133, 2009.

Njage, P.M.K.; Dolci, S.; Jans, C.; Wangoh, J.; Lacroix, C.; Meile, L. Biodiversity and enterotoxigenic potential of staphylococci isolated from raw and spontaneously fermented camel milk. British Microbiology Research Journal, 3: 128-138, 2013.

Normanno, T.G.; Salandra, G.L.A.; Dambrosio, A.; Quaglia, N.C.; Corrente, M.; Parisi, A.; Santagada, G.; Firinu, A.; Crisetti, E.; Celano, G.V. Occurrence, characterization and antimicrobial resistance of enterotoxigenic Staphylococcus aureus isolated from meat and 
dairy products. Journal of Food Microbiology, 115(3): 290-296, 2007.

Oliver, S.; Boor, K.; Murphy, S.C.; Murinda, S.E. Food safety hazards associated with consumption of raw milk. Foodborne Pathogens and Disease, 6(7): 793-806, 2009.

Omoe, K.; Hu, D.L.; Takahashi-Omoe, H.; Nakane, A.; Shinagawa, K. Comprehensive analysis of classical and newly described Staphylococcal superantigenic toxin genes in Staphylococcus aureus isolates. FEMS Microbiology Letters, 246(2): 191-198, 2005.

Ono, H. K.; Sato'o, Y; Narita, K.; Naito, I.; Hirose, S.; Hisatsune, J.; Asano, K.; Hu, D. L.; Omoe, K.; Sugai, M.; Nakane, A. Identification and characterization of a novel staphylococcal emetic toxin. Applied and Environmental Microbiology, 81: 7034-7040, 2015.

Orden, J.A.; Goyache, J.; Hernandez, J.; Domenech, A.; Suarez, G.; Gomez-Lucia, E. Detection of enterotoxins and TSST-1 secreted by Staphyococcus aureus isolated from ruminant mastitis. Comparison of ELISA and immunoblot. Journal of Applied Bacteriology, 72(6): 486-489, 1992.

Otero, A.; García, M.L.; García, M.C.; Moreno, B.; Bergdoll, M.S. Production of Staphylococcal enterotoxins $\mathrm{C} 1$ and $\mathrm{C} 2$ and thermonuclease throughout the growth cycle. Applied and Environmental Microbiology, 56(2): 555-9, 1990.

Pales, A.P.; Santos, K.J.G.; Figueiras, E.A.; Melo, C.S.A importância da contagem de células somáticas e contagem bacteriana total para a melhoria da qualidade do leite no Brasil. Revista Eletrônica Faculdade Montes Belos, 1(2): 162-173, 2005.

Passos, M.H.C.R.; Kuaye, A.Y. Relato de surtos de intoxicação alimentar provocada por consumo de bolo contaminado por Staphylococcus aureus importância da higiene dos manipuladores e condições de conservação do alimento na prevenção da doença. Revista do Instituto Adolfo Lutz, 56(1): 71-76, 1996.

Pelisser, M.R.; Klein, C.S.; Ascoli, K.R.; Zotti, T.R.; Arisil, A.C.M. Occurrence of Staphylococcus aureus and multiplex PCR detection of classic enterotoxin genes in cheese and meat products. Brazilian Journal of Microbiology, 40(1): 145-148, 2009.

Pereira, M.L.; Carmo, L.S; Santos, E.J.; Pereira, J.L.; Bergdoll, M.S. Enterotoxin $\mathrm{H}$ in
Staphylococcal food poisoning. Journal of Food Protection, 59(5): 559-561, 1996.

Poulsen, L.K. Hints for diagnosis. Chemical Immunology and Allergy, 101: 59-67, 2015.

Queiroga, R.C.R.E.; Santos, B.M.; Gomes, A.M.P.; Monteiro, M.J.; Teixeira, S.M.; Souza, E.L.; Pereira, C.J.D.; Pintado, M.M.E. Nutritional, textural and sensory properties of Coalho cheese made of goats', cows' milk and their mixture. Food Science and Technology, 50(2): 538-44, 2013.

Reiser, R.F.; Robbins, R.N.; Khoe, G.P.; Bergdoll, M.S. Purification and some physicochemical properties of toxic-shock toxin. Biochemistry, 22(16): 3907-3912, 1983.

Reiser, R.F.; Robbins, R.N.; Noleto, A.L.; Khoe, G.P.; Bergdoll, M.S. Identification, purification, and some physicochemical properties of Staphylococcal enterotoxin C3. Infection and Immunity, 45(3): 625-630, 1984.

Ribeiro, M.E.R.; Petrini, L.A.; Aita, M.F.; Balbinotti, M.; Stumpf, JR. W.; Gomes, J.F.; Schramm, R.C.; Martins, P.R.; Barbosa, R.S. Relação entre mastite clínica, subclínica infecciosa e não infecciosa em unidades de produção leiteiras na região sul do Rio Grande do Sul. Revista Brasileira de Agrociência, 9(3): 287-290, 2003.

Ribeiro, A.C.; Ribeiro, S.D.A. Specialty products made from goat milk. Small Ruminant Research, 89(2-3): 225-33, 2010.

Robern, H.; Stavric, S.; Dickie, N. The application of QAE-Sephadex for the purification of two Staphylococcal enterotoxins. I. Purification of enterotoxin C2. Biochimica et Biophysica Acta, 393(1): 148-58, 1975.

Sahyon, N.R. Nutrition education for the healthy elderly population: Isn't time? Journal of Nutrition Education and Behavior, 34(1): 42-7, 2002.

Santana, E.H.W.; Beloti, V.; Aragon-Alegro, L.C.; Mendonça, M.B.O.C. Estafilococos em alimentos. Arquivos do Instituto Biológico, 77(3): 545-555, 2010.

Santos, B.M.; Oliveira, M.E.G.; Sousa, Y.R.F.; Madureira, A.R.M.F.M.; Pintado, M.M.E.; Gomes, A.M.P.; Souza, E.L.; Queiroga, R.C.R.E. Caracterização físico-química e sensorial de queijo de coalho produzido com mistura de leite de cabra e de leite de vaca. Revista do Instituto Adolfo Lutz, 70(3): 302-310, 2011. 
Scherrer, D.; Corti, S.; Muehlherr, J.E.; Zweifel, C.; Stephan, R. Phenotypic and genotypic characteristics of Staphylococcus aureus isolates from raw bulk-tank milk samples of goats and sheep. Veterinary Microbiology, 101(2): 101-7, 2004.

Schlievert, P.M.; Jablonski, L.M.; Roggiani, M.; Sadler, I.; Callantine, S.; Mitchell, D.T.; Ohlendorf, D.H.; Bohach, G.A. Pyrogenic toxin superantigen site specificity in toxic shock syndrome and food poisoning in animals. Infection and Immunity, 68(6): 3630-3634, 2000.

SES - SECRETÁRIA DE SAÚDE DE PERNAMBUCO. Vigilância Epidemiológica das Doenças Transmitidas por Alimentos. Disponível em: <http://portal.saude.pe.gov .br/programa/secretaria-executiva-devigilância-emsaude/vigilanciaepidemiologica-das -doencas-0>. Acesso em: 18 jun. 2018.

Shafer, W.M.; Iandolo, J.J. Staphylococcal Enterotoxin A: a Chromosomal Gene Productt. Applied and Environmental Microbiology, 36(2): 389-91, 1978.

Shalita, Z.; Hertman, I.; Sand, S. Isolation and characterization of a plasmid involved with enterotoxin B production in Staphylococcus aureus. Journal of Bacteriology, 129(1): 317-25, 1977.

Silva, L.C.A.; Pessoa, D.A.N.; Silva, L.S.A.; Aquino, S.S.; Macêdo, M.M.S.; Mattos, R.A.T.; Garino Júnior, F. Avaliação in vitro da sensibilidade de estirpes de Staphylococcus spp. isoladas de mastite caprina frente a desinfetantes comerciais. Arquivo do Instituto Biológico, 82: 1-4, 2015.

Slačanac, V.; Božanić, R.; Hardi, J.; Szabó, J. R.; Lučan, M.; Krstanović, V. Nutritional and therapeutic value of fermented caprine milk. International Journal of Dairy Technolog, 63(2): 171-89, 2010.

Soriano, J.M.; Font, G.; Moltó, C.; Mañes, J. Enterotoxigenic staphylococci and their toxins in restaurant foods. Trends in Food Science \& Technology, 13(2): 60-7, 2002.

Spanu, V.; Spanu, C.; Virdis, S.; Cossu, F.; Scarano, C.; De Santis, E. P. Virulencefactors and genetic variability of Staphylococcus aureus strains isolated fromraw sheep's milk cheese. International Journal of Food Microbiology, 153(1-2): 53-7, 2012.
Stamford, T.L.M.; Silva, C.G.M.; Mota, R.A.; Cunha Neto, A. Enterotoxi-genicidade de Staphylococcus spp. isolados de leite in natura. Ciência e Tecnologia de Alimentos, 26(1): 41-5, 2006.

Stewart, G.C. Staphylococcus aureus. In Foodborne pathogens: Microbiology and Molecular Biology; Fratamico, P.M., Bhunia, A.K., Smith, J.L., Eds.; Caister Academic Press: Norfolk, 2005, p.273-284.

Tong, S.Y.; Davis, J.S.; Eichenberger, E.; Holland, T.L.; Fowler, JR.V.G. Staphylococcus aureus infections: epidemiology, pathophysiology, clinical manifestations, and management. Clinical Microbiology Reviews, 28(3): 60361, 2015.

Todd, J.; Fishaut, M.; Kapral, F.; Welch, T. Toxicshock syndrome associated with phage-groupI Staphylococci. Lancet, 2(8100): 1116-8, 1978.

Tomasi, L.C.; Spazziani, M.L. Construindo atitudes para uma vida saudável: uma experiência educativa com alunos do ensino fundamental. Revista Simbio-Logias, 1(2): 115,2008

Tremaine, M.T.; Brockman, D.K.; Betley, M.J. Staphylococcal enterotoxin A gene (sea) expression is not affected by the acessory gene regulator (agr). Infection and Immunity, 61(1): 356-9, 1993.

Tutsuura, S.; Murata, M. Temperature dependence of Staphylococcal enterotoxin A production by Staphylococcus aureus. Bioscience Biotechnology and Biochemistry, 77(1): 3037, 2013.

Velázquez-Meza, M.E. Staphylococcus aureus methicillin-resistant: emergence and dissemination. Salud Pública de México, 47(5): 381-7, 2005.

Wang, X.; Meng, J.; Zhang, J.; Zhou, T.; Zhang, Y.; Yang, B.; Xi, M.; Xia, X. Characterization of Staphylococcus aureus isolated from powdered infant formula milk and infant rice cereal in China. International Journal of Food Microbiology, 153(1-2): 142-147, 2012.

Wieneke, A.; Gilbertr, J. Comparison of four methods for the detection of staphylococcal enterotoxin in foods from outbreaks of food poisoning. International Journal of Food Microbiology, 4(2): 135-43, 1987.

Wieneke, A.A.; Roberts, D.; Gilbert, R.J. Staphylococcal food poisoning in the United 
Kingdom, 1969-1990. Epidemiology and Infection, 110(3): 519-31, 1993.

Wilson, G.J.; Seo, K.S.; Cartwright, R.A.; Connelley, T.; Chuangsmith, O.N.; Merriman, J.A.; Guinane, C.M.; Park, J.Y.; Bohach, G.A.; Schlievert, P.M.; Morrison, W.I.; Fitzgerald, J.R. A novel core genome-encoded superantigen contributes to lethality of community-associated MRSA necrotizing pneumonia. Plos Pathogens, 7(10): 2011.

WORLD HEALTH ORGANIZATION-WHO.

Foodborne diseases. 2017. Disponível em $<$ http://www.who.int/topics/foodborne_disea ses/en/>. Acesso em: 17 jun. 2018.
Xing, X.; Zhang, Y.; Wu, Q.; Wang, X.; Ge, W.; $\mathrm{Wu}, \mathrm{C}$. Prevalence and characterization of Staphylococcus aureus isolated from goat milk processing plants. Food Control, 59: 644-50, 2016.

Zecconi, A.; Hahn, G. Staphylococcus aureus in raw milk and human health risk. Bulletin of IDF, 345: 15-8, 2000.

Zweifel, C.; Rusch, M.; Corti, S.; Stephan, R. Determination of various microbiological parameters in raw milk and raw milk cheese produced by biofarms. Archiv für Lebensmittel Hygiene, 57: 13-6, 2006. 